\title{
ENSINO DA LÍNGUA PORTUGUESA COMO SEGUNDA LÍNGUA PARA JOVENS E ADULTOS SURDOS: RELATO DE UMA EXPERIÊNCIA
}

\author{
Ana Luisa Borba Gediel é Professora Adjunta II, na área de LIBRAS, do Departamento de Letras da Universidade Federal de Viçosa - UFV. \\ Coordenadora do Curso de Extensão em LIBRAS - CELIB/UFV. Coordenadora do Projeto EAMES. \\ E-mail: ana.gediel@ufv.br
}

Michelle Nave Valadão é Professora Adjunta I, na área de LIBRAS, do Departamento de Letras da Universidade Federal de Viçosa - UFV. Coordenadora do projeto EAMES.

E-mail: michelle.nave@ufv.br

Roselia Aparecida Gonçalves é graduada em Letras e Especialista em Educação pelo Instituto Federal de Educação, Ciência e Tecnologia de Santa Catarina. Voluntária no projeto EAMES.

E-mail: roseliagoncalves@yahoo.com.br

Maria Célia de Freitas Andrade é graduanda do sexto período do curso de Pedagogia da Universidade Federal de Viçosa. Voluntária no projeto EAMES

E-mail: ncmcandrade@gmail.com

Elisa Maria Almeida Costa é Gestora de Cooperativas e Mestre em Economia Doméstica pela Universidade Federal de Viçosa - UFV. Voluntária no projeto EAMES.

E-mail: elisacoop@yahoo.com.br

\section{RESUMO}

O presente artigo relata uma experiência de ensino da Língua Portuguesa como segunda língua para surdos, por meio da LIBRAS, descrevendo as particularidades envolvidas nesse processo.

\begin{abstract}
This article aims to report an experience in teaching Portuguese as a second language for the deaf through LIBRAS - Brazilian Sign Language - describing the particularities involved in this process.
\end{abstract}

\section{1) Introdução}

O ensino da Língua Portuguesa vem sendo alvo de pesquisas em Linguística Aplicada, quando se trata de discutir questões em torno do uso da língua, ensino e aprendizagem, ao entender que é uma área interdisciplinar, mediadora de investigações em busca da solução de problemas acerca da linguagem como elemento processual, como pode ser observado em Lopes (1996). Dentre as diversas demandas, reflete-se a respeito do estudo da Língua Portuguesa como língua materna. Entretanto, o foco pode ser deslocado para adentrar as questões de pesquisa, as quais circundam o meio social e educacional, vislumbrando-a como segunda língua. Esse caso específico constitui-se na temática da educação de surdos.

A aquisição da Língua Portuguesa para os sujeitos surdos, como segunda língua, é extremamente complexa, pois envolve aspectos linguísticos, históricos, educacionais e sociais, uma vez que aqueles adquirem a LIBRAS - Língua Brasileira de Sinais - como 
primeira. A questão não está centrada na ideia de deficiência ou dificuldades de aprendizagem, mas na diferenciação da estrutura linguística das duas línguas e no processo de aquisição e aprendizagem vivenciadas pelos surdos. Tais situações envolvem as formas de convivência, os espaços comuns de uso e de circulação da Língua Portuguesa e as interações cotidianas. A problemática centra-se em como são construídas essas experiências, uma vez que os surdos necessitam do domínio linguístico de ambas as línguas, de Sinais e Portuguesa, para uma interação efetiva em sociedade.

O estabelecimento de uma língua permite a socialização e a sociabilidade. Para as pessoas surdas, isso se constrói a partir do uso da LIBRAS, no Brasil, a qual permitirá o seu desenvolvimento linguístico, cognitivo e social. A língua é de fundamental importância para o ser humano, pois é a partir dela que o mesmo pode se socializar com seus pares; construir sua identidade; apropriar-se de conhecimentos relativos ao ensino-aprendizagem no âmbito educacional e, consequentemente, transpôlos às práticas sociais. Assim, a LIBRAS, uma vez entendida como a primeira língua do surdo, deverá ser o meio de instrução por excelência, que será concebido como instrumento para aprender a metalinguagem da segunda língua e de outras línguas a que o sujeito tenha acesso, como podemos notar em Rodrigues et al. (2004).

Levando em consideração as questões linguísticas e sociais dos sujeitos surdos, o objetivo deste artigo centra-se no relato de uma experiência com oficinas bilíngues, realizadas a partir do desenvolvimento de um projeto voltado a jovens e adultos surdos, no que se refere ao ensino e aprendizagem da Língua Portuguesa por meio da LIBRAS.

\section{2) Considerações a partir do ensino da Língua Portuguesa para surdos}

A importância de uma língua na construção, integração e socialização de saberes envolve diversas manifestações de uso linguístico, as quais estão inseridas em contextos sociais, políticos, educacionais, econômicos, como pode ser observado em Celani (2000). A articulação e a mediação dos saberes inseridos nesses contextos, por meio da LIBRAS, são essenciais para a construção identitária e cultural das pessoas surdas. Desse modo, no campo da Linguística Aplicada, interessa compreender o conjunto de situações linguísticas vivenciadas pelos sujeitos surdos, apontando possíveis mudanças nas práticas educacionais.

Com a difusão da Língua de Sinais nas últimas décadas no Brasil, a discussão acerca da educação de surdos vem sendo ampliada, tanto no que se refere ao fortalecimento do movimento surdo e criação de uma legislação específica, como na reflexão de profissionais da educação a respeito das práticas pedagógicas. Nesse contexto, a partir de 1980, políticas públicas foram elaboradas em prol da comunidade surda. Uma das medidas foi a proposta do bilinguismo, que começou a ser implementada na década de 90, como podemos notar em Goldfeld (2002). 
O bilinguismo constitui-se para além das perspectivas de aplicação de uma abordagem educacional, pois visa resgatar os direitos da pessoa surda, referentes à interação social e à acessibilidade em diferentes âmbitos. Essa abordagem privilegia a formação linguística do sujeito surdo a partir da evidência de suas próprias características, ou seja, permite:

A aquisição da Língua de Sinais como primeira língua de forma a oferecer-lhe um meio natural de aquisição linguística, visto que se apresenta como língua de modalidade espaço-visual, não dependendo, portanto, da audição para ser adquirida (FERNANDES, 2003, p. 30-31).

A aquisição linguística proposta por Fernandes (2003) considera a possibilidade de aprendizagem do sujeito surdo a partir das condições de modalidade da sua língua. Nesse caso, o aspecto visual contribui significativamente para que as experiências cotidianas sejam ressignificadas a cada momento de aprendizagem da primeira língua. Importa ressaltar que o uso e a divulgação da Língua de Sinais pelos surdos brasileiros teve amplitude e alcançou amparo institucional por meio da legislação, com o reconhecimento da LIBRAS como a primeira língua. Isso ainda influenciou a representatividade da LIBRAS ao se mencionar, por exemplo, no parágrafo único da Lei 10.436/2002 que "a Língua Brasileira de Sinais - LIBRAS não poderá substituir a modalidade escrita da Língua Portuguesa" (BRASIL, 2002). Por meio dessa afirmação, entende-se que o sujeito surdo tem a Língua de Sinais como sua primeira língua e a Língua Portuguesa, na modalidade escrita, como sua segunda, como pode ser observado em Salles et al. (2004). Essa consideração abarca uma das principais características do ensino bilíngue.

A proposta da abordagem bilíngue vem sendo debatida por vários autores, tais como Correia e Fernandes (2005), Fernandes e Rios (1998), Ferreira Brito (1993), Gesser (2009), Giordani (2006), Góes (1996), Quadros (2005), que destacam a abertura de um leque de possibilidades quando ocorre a aquisição da Língua de Sinais, o mais cedo possível, como primeira língua. Esta deverá fornecer o arcabouço linguístico para o acesso à língua majoritária e aos conhecimentos sistematizados, priorizando que a educação seja construída a partir da Língua de Sinais; além de valorizar a cultura dos surdos e sua real inserção na sociedade, como podemos notar em Dizeu e Caporali (2005).

Outro aspecto a ser mencionado para a efetivação do bilinguismo, referente ao trabalho educacional, é o respeito às especificidades desses sujeitos. Embora no Brasil os surdos façam parte de um grupo de cidadãos que têm o português como segunda língua, os aspectos envolvidos em sua aquisição envolvem particularidades que devem ser ponderadas, pois são determinantes nesse processo. Dentre essas particularidades, cabe destacar que o ambiente de ensino da Língua Portuguesa ocorre, na cultura ocidental, a partir da valorização de um formato de comunicação verbal, em que os diálogos e informações cotidianas, geralmente, são predominantes. Esse ambiente, para 
os surdos, é um ambiente não natural de língua. Embora eles convivam com pessoas que fazem uso da língua portuguesa, a condição física de privação auditiva não lhes permite "imersão" no sentido em que o termo é empregado nas propostas de aquisição de segunda língua com base no enfoque natural (programas de imersão), de acordo com Quadros (1998). Esse processo não acontece em um ambiente linguístico permeado pela construção de diálogos espontâneos de forma natural. Portanto, o ensino e aprendizagem da Língua Portuguesa será, então, apenas da sua modalidade escrita, desde a compreensão de frases do cotidiano à elaboração de uma produção de materiais escritos, considerando-se os efeitos das modalidades e o acesso pelos surdos a elas, segundo Salles et al. (2004).

$\mathrm{O}$ fato de as pessoas surdas utilizarem uma forma de comunicação específica remete ao entendimento e ao compartilhamento de significados, os quais são semelhantes a respeito das particularidades do que é ser surdo. As Línguas de Sinais estão organizadas "conforme as propriedades dos sistemas de percepções dos indivíduos e não necessariamente de acordo com a comunidade linguística em que a pessoa nasceu" (KEATING; MIRUS, 2003, p. 696). Dentro dessa perspectiva, os sujeitos surdos, por meio de sua língua, partilham motivações e significações em determinado tempo e espaço, de acordo com a complexidade linguística apresentada na Língua de Sinais. Essas manifestações linguísticas proporcionam a construção de vínculos essenciais à cultura e à identidade.

Ao considerar as intervenções linguísticas na constituição do espaço social, retoma-se a ideia de que as relações de sociabilidade são realizadas entre surdos e entre surdos e ouvintes, sendo que entre esses últimos ocorre, na maioria das vezes, a partir da língua escrita. Assim, a Língua Portuguesa torna-se um importante artefato de mediação comunicativa e de convivência social. No entanto, os espaços de aprendizagem da mesma ainda são bastante restritos aos sujeitos surdos, geralmente, devido à falsa prerrogativa de que estes têm dificuldades em sua aprendizagem. Tratando-se da modalidade escrita da Língua Portuguesa, cujo canal de recepção é a via visual, teoricamente, não haveria a interferência da condição auditiva para sua aquisição. Entretanto, os surdos ainda se deparam com obstáculos de cunho linguístico e social. Ao desenvolver práticas de ensino da Língua Portuguesa baseadas exclusivamente em ouvintes, na maioria das vezes, é desconsiderado que esses adquirem o português falado de forma natural e que a modalidade escrita, com particularidades, é a representação gráfica da modalidade oral-auditiva da Língua Portuguesa. No caso dos surdos, eles, ao entrarem em contato com o português escrito, na maioria das vezes, não são familiarizados com a modalidade oral da segunda língua.

Ainda, partindo do pressuposto da LIBRAS como primeira língua, a situação dos surdos continua permeada de especificidades, pois, em decorrência de todo o histórico de exclusão social e linguística de não valorização da Língua de Sinais, muitos foram submetidos a práticas comunicativas artificiais que não possibilitaram a apropriação plena da LIBRAS como primeira língua, segundo Lodi e Moura (2006). 
Essa situação se agrava ao considerarmos jovens e adultos surdos. Muitos, ao buscarem a aprendizagem da língua escrita, continuam deparando-se com metodologias que não contemplam todas as suas potencialidades. Embora seja inegável, nesses casos, a contribuição de metodologias de ensino de línguas para estrangeiros e de Língua Portuguesa para ouvintes, o uso das mesmas, bem como dos seus recursos didáticos, precisam ser ressignificados de forma a contemplar os interesses das pessoas surdas. Ao se valer de tais metodologias, deve ser levado em consideração, por exemplo, que os adultos surdos, ao se predisporem ao aprendizado do português escrito, não dominam um sistema de escrita prévio, ao contrário dos adultos ouvintes.

Embora as Línguas de Sinais também possuam uma representação gráfica, baseada em um sistema de escrita visual e direta dos sinais, denominado SignWriting, a maioria das pessoas, inclusive os próprios surdos, ainda não dominam esse sistema. Stokoe (1960), ao estudar a estrutura linguística da Língua Americana de Sinais, nomeou quirema o segmento mínimo sinalizado, correspondente ao fonema da fala. No Brasil, os estudos com a representação escrita dos quiremas, que compõem os sinais da LIBRAS, por meio do SignWriting, são recentes e pontuais. Esse sistema vem sendo usado principalmente em situações de pesquisas por autores como Strobel (1995), para escrever histórias e contos infantis em LIBRAS; por Stumpf (1998), em cursos de informática e LIBRAS para crianças surdas; por Quadros (1999), para documentar a gramática da LIBRAS; e por Capovilla, Raphael e Luz (2001), para documentar os sinais da LIBRAS em dicionários. Não é comum o uso dessas representações, escritas em SignWriting, em suas práticas cotidianas, como acontece, por exemplo, com a agregação, ao português, de palavras escritas em línguas estrangeiras.

Dessa forma, a condição dos surdos torna-se ainda mais particular, uma vez que deverão aprender a modalidade escrita da segunda língua sem dominarem a modalidade gráfica da sua primeira língua e, muitas vezes, sem terem se apropriado plenamente dela.

Atrelado a todas essas adversidades, no Brasil, os recursos disponíveis aos surdos para a aprendizagem da segunda língua - o português escrito - ainda são escassos. Os materiais didáticos e paradidáticos em LIBRAS, quando disponíveis, não são acessíveis a todos, ocasionando assim grandes dificuldades para esses estudantes, conforme Menezes (2012).

Frente a essas considerações, surgiu a possibilidade de articular os saberes vinculados à construção da linguagem com o processo de ensino e aprendizagem dos sujeitos surdos.

\section{3) Contexto da pesquisa}

No ano de 2011, um grupo de alunos surdos ingressou no Cursinho Popular do Diretório Central dos Estudantes da Universidade Federal de Viçosa - UFV. Esse cursinho é coordenado e desenvolvido por acadêmicos das diferentes licenciaturas da 
universidade. Tais acadêmicos, após cursarem a disciplina de LIBRAS, perceberam que os alunos surdos, que frequentavam o cursinho, haviam terminado o ensino médio, porém não dominavam a língua portuguesa escrita, liam apenas palavras isoladas e não conseguiam elaborar frases.

Os alunos surdos apresentavam um histórico de fracasso em sua trajetória escolar, pois, embora tivessem passado por todas as etapas da escolarização básica, o ensino não lhes foi proporcionado de maneira exitosa a fim de lhes permitirem autonomia, empregabilidade e acesso ao ensino superior. Frente às adversidades, enfrentadas nas suas trajetórias escolares e sociais, os jovens e adultos surdos sentiam o desejo de aprender Língua Portuguesa de modo significativo, de forma que esse aprendizado pudesse conduzi-los efetivamente ao mundo letrado.

Assim surgiu a necessidade de criação de um espaço o qual incluísse efetivamente esses sujeitos. Iniciou-se desse modo o projeto, registrado na UFV, Ensino e Aprendizagem e Metodologias de Ensino para Surdos - EAMES - para a realização de oficinas bilíngues, priorizando o ensino e a aprendizagem da Língua Portuguesa como segunda língua. Tais oficinas foram oferecidas a três alunos surdos, com idade entre dezenove e vinte e três anos, de ambos os gêneros.

O projeto contou com acadêmicos do curso de Pedagogia, de diferentes licenciaturas, uma professora voluntária, formada em Letras e especialista em educação de jovens e adultos, e duas docentes da área de LIBRAS da UFV. Uma das acadêmicas do curso de Pedagogia atuou no papel de intérprete em LIBRAS/Língua Portuguesa. Os demais participantes atuaram na criação e aplicação de recursos didáticos e metodologias de ensino e aprendizagem para surdos.

O trabalho foi desenvolvido em sala de aula disponibilizada pelo Departamento de Letras da UFV durante o ano letivo de 2011 e o primeiro semestre de 2012. As aulas tinham período de duração de três horas e ocorriam duas vezes por semana.

No desenvolvimento do projeto, primeiramente, foi construído um grupo de capacitação aos discentes para a atuação nas oficinas a serem ministradas aos alunos surdos. Tal iniciativa objetivou que os acadêmicos se apropriassem dos conteúdos das diversas áreas dos conhecimentos por meio da LIBRAS, primeira língua dos alunos surdos, para posteriormente proporcionarem a troca de saberes.

Eram agendados encontros semanais entre os participantes e as docentes coordenadoras do projeto. Neles eram discutidos os planejamentos das oficinas, os planos de aula, as dinâmicas propostas e os resultados alcançados.

Os graduandos participaram de grupos de estudos, buscando subsídios teóricos e metodológicos para a educação de jovens e adultos surdos, de modo a oportunizar a aquisição da Língua Portuguesa. Tais métodos priorizavam os aspectos visuais e o uso de materiais concretos e alternativos, contribuindo para uma aprendizagem mais significativa que considerasse a natureza da língua de sinais - visuoespacial. Esses acadêmicos tinham como meta a criação de metodologias que 
desenvolvessem nos alunos surdos, de acordo com Freire (1979; 1992), um espírito de cidadania e participação social, estimulando a criticidade, de forma dialógica e participativa, respeitando os conhecimentos que os mesmos traziam como sujeitos culturais, sociais e históricos.

Buscou-se o desenvolvimento de um ensino efetivo, prazeroso, norteado pela abordagem bilíngue, de forma a reconhecer e valorizar a LIBRAS como primeira língua, a língua de instrução, dos alunos surdos. Por meio da LIBRAS, visamos promover a aquisição da Língua Portuguesa, em sua modalidade escrita, como segunda língua.

\section{4) Práticas desenvolvidas para o ensino-aprendizagem da Língua Portuguesa como segunda língua para jovens e adultos surdos}

A partir da leitura da literatura específica da área, como Cruz e Dias (2009), Góes (1996), Goldfeld (2002), Lacerda (2006), Lodi e Moura (2006), Quadros (1997; 1998; 2005), Salles et al. (2004) e das discussões promovidas pelos acadêmicos, constatou-se a existência de poucos trabalhos abordando o ensino da Língua Portuguesa como segunda língua para jovens e adultos surdos. Entretanto, tais literaturas evidenciaram que a realidade educacional dos surdos no Brasil permanece conflitante, sendo comum que muitos alunos apresentem defasagem na leitura e escrita da Língua Portuguesa, mesmo após anos de permanência nos espaços escolares.

Por conseguinte, após concluírem o ensino médio, poucos são os surdos que ingressam no ensino superior e, no Brasil, os dados sobre a presença de pessoas surdas e suas condições nas instituições de ensino superior são incipientes, de acordo com Cruz e Dias (2009). Essa situação também se repete no campo da empregabilidade, dificultando seu ingresso nos espaços de trabalho e privando-as do exercício da cidadania de modo pleno. Fora dos ambientes laborais e educacionais, restam-lhes poucos espaços onde possam dar continuidade às suas vivências sociais e práticas culturais.

Diante dessa realidade, foram pensadas oficinas bilíngues que pudessem atender, segundo Lodi e Moura (2006), a necessidade de criação de espaços onde a LIBRAS circule livremente, ocupando um lugar de reflexão e compreensão dos diversos discursos presentes e articulando o ensino e a aprendizagem da Língua Portuguesa como segunda língua.

Ao compartilhar, conhecer e vivenciar a cultura e o espaço onde a LIBRAS circula, os graduandos puderam oferecer oficinas que atendessem aos relatos das principais situações cotidianas em que os surdos sentiam necessidade de saber ler e escrever na sua segunda língua - o português escrito.

Dentre as diversas oficinas realizadas, destacaremos duas delas. A temática da primeira foi culinária, focando a elaboração e produção de receitas, e abrangendo o desenvolvimento de conceitos de quantidades, vocabulário, leitura e produção de textos. 
Já a segunda, explorou uma situação de compra e venda. Nessa foram incluídas, além da escrita e leitura de diversos gêneros textuais, também noções matemáticas - em uma abordagem interdisciplinar.

Seguindo o preceito da LIBRAS como língua de instrução, inicialmente, a receita foi apresentada nessa língua. A partir disso, foram desencadeadas discussões acerca do modo de preparo e suas variações quanto aos ingredientes, medidas e quantidades. Em seguida, foram apresentados os produtos e realizada a exploração de seus rótulos para o reconhecimento das imagens gráficas e das palavras. $\mathrm{O}$ uso de rótulos e embalagens de produtos buscou promover um letramento visual, estimulando a leitura das mensagens visuais das imagens. A respeito dos recursos visuais, Nery e Batista (2004), Sofiato (2005), Gesueli e Moura (2006), dizem que, desde muito cedo, aprendemos a ler essas imagens e discutir os usos e significações das mesmas no contexto educacional. $\mathrm{O}$ uso de imagens visuais constitui-se de um recurso fundamental para o desenvolvimento cognitivo do aluno surdo, além de ser um recurso pedagógico adequado ao processo de ensino e aprendizagem do mesmo. Por fim, os alunos elaboraram, em Língua Portuguesa, a produção escrita da receita.

Em se tratando da elaboração de textos por alunos surdos, Salles et al. (2004) afirmam que o texto escrito não pode se restringir a transmitir informações estruturais e lexicais na língua, mas cabe a ele assumir o papel de contextualizador, trazendo aspectos pragmáticos, sociolinguísticos e culturais. Logo, é necessário que esses textos sejam autênticos, contenham temas relacionados à experiência dos aprendizes, levando a um maior envolvimento pessoal e provocando reações e manifestações, e que também estejam associados a imagens.

Ainda de acordo com os interesses dos alunos, a segunda atividade simulou situações de compra e venda. O objetivo foi o reconhecimento e a identificação do dinheiro brasileiro (cédulas e moedas), a efetuação de operações matemáticas (adição e subtração), e a ampliação de leitura e vocabulário - visando o ensino do português.

Foram promovidas situações que simulassem um mercado. As aulas foram iniciadas com a apresentação de diversos encartes e jornais de propagandas e ofertas de estabelecimentos comerciais da região, explorando os diversos gêneros textuais. Esses recursos permitiram a exploração dos produtos, o reconhecimento e a comparação dos preços entre diferentes estabelecimentos e marcas.

Em seguida, os alunos transformaram a sala de aula em um ambiente de mercado: colocaram etiquetas com preços em produtos; organizaram o caixa; elaboraram lista de compras; e simularam situações de compra e venda. Todos eles reconheceram as notas e moedas, porém apresentaram dificuldades em realizar operações matemáticas de adição e subtração, envolvendo a soma dos valores e a subtração para o troco.

Com as orientações em LIBRAS e a reelaboração das atividades na segunda língua - Língua Portuguesa na modalidade escrita - os alunos alcançaram os objetivos propostos pela oficina. Acerca disso, Rocha (2010) ressalta, ainda, que o processo de 
ensino da Língua Portuguesa para alunos surdos deve ocorrer a partir de recursos concretos e visuais e, para isso, o professor irá atuar como mediador, possibilitando a compreensão dos conteúdos por meio dos recursos utilizados.

Em seguida, o grupo colocou em prática as atividades simuladas em sala de aula. Foi disponibilizada a cada aluno a quantia de dez reais $(\mathrm{R} \$ 10,00)$ para a compra de produtos que viriam a ser utilizados na elaboração de uma receita, conforme a atividade anterior. Os alunos calcularam a quantidade de produtos, pesquisaram preços, planejaram gastos e elaboraram listas de compras. Já em uma situação real, no mercado, realizaram as compras, calcularam o preço, efetuaram o pagamento e conferiram o troco, sem dificuldades. Essa experiência pedagógica vai ao encontro das afirmações de Gesueli e Moura (2006), as quais ressaltam a importância do uso de materiais concretos e recursos visuais no processo de construção do conhecimento de alunos surdos.

Essa atividade proporcionou diversas discussões ao grupo, pois os alunos foram unânimes ao relatarem inseguranças que vivenciavam em situações como essa. Disseram que, em ocasiões semelhantes, optavam pela companhia de ouvintes e, quando sozinhos, não conferiam o troco. Esses relatos apontam que muitos surdos ainda são colocados à margem da sociedade, por não possuírem autonomia necessária para realizar atividades cotidianas que exijam a leitura e a escrita. Frente a essas dificuldades, Lacerda (2006) afirma que é necessária a elaboração de propostas educacionais que atendam às especificidades dos sujeitos surdos, favorecendo o desenvolvimento efetivo de suas capacidades de acordo com o contexto social e linguístico.

Um dos alunos surdos comentou que, após frequentar as oficinas, passou a fazer uso, em suas atividades cotidianas, dos conceitos trabalhados. O desenvolvimento das oficinas, por meio de vivências socioculturais, permitiu sua aplicabilidade em situações de uso cotidiano. A utilização da Língua Portuguesa escrita em práticas sociais é uma tarefa que tem relevância no dia a dia, uma vez que são inúmeras as situações em que seu uso é necessário como, por exemplo, encontrar informações em um catálogo telefônico, em uma conta de luz ou em uma bula de remédio, como pode ser observado em Vital (2011).

Visando promover a interação social do grupo e despertar o interesse pelos conteúdos programados, as atividades foram planejadas de acordo com as preferências dos alunos e desenvolvidas em LIBRAS. Essa ação é corroborada por Veloso (2006) ao afirmar que, primeiramente, é importante que o aluno esteja engajado na aprendizagem da segunda língua e, para isso, a sua primeira língua não pode ser considerada inferior. Tornar-se bilíngue é um processo que vai além do conhecimento da gramática da segunda língua; é preciso compartilhar, conhecer e vivenciar a cultura e o espaço onde essa língua circula para se apropriar dela plenamente.

Assim, por meio da LIBRAS, interdisciplinarmente, com conteúdos referentes às Ciências Humanas e Exatas, foi possível promover práticas de ensino da Língua Portuguesa como segunda língua para esses alunos surdos. 


\section{5) Considerações finais}

Diante do exposto, conclui-se, por meio das experiências de atuação pedagógica, que fatores como o percurso histórico de não reconhecimento e valorização da Língua de Sinais como uma língua natural, o uso de metodologias de ensino inadequadas e a carência de recursos didáticos em LIBRAS fazem com que os surdos sigam com dificuldades de aquisição da Língua Portuguesa escrita.

O ensino da Língua Portuguesa, como segunda língua para os surdos, deve levar em consideração as potencialidades desses sujeitos no que se refere aos aspectos históricos e culturais, à legislação específica e às abordagens educacionais. É preciso reconhecê-los como sujeitos multiculturais, que possuem cultura e identidade próprias, representadas, principalmente, por uma língua de modalidade visual espacial. Além disso, importa reconhecê-los também como cidadãos brasileiros que convivem com a Língua Portuguesa. Nesse sentido, a aprendizagem da segunda língua tem uma função social, a qual se insere na perspectiva bilíngue. Desse modo, torna-se necessário que a LIBRAS seja reconhecida em seu valor social, não ocupando um papel submisso frente à Língua Portuguesa, mas sim um posto central de primeira língua, a qual possibilitará a aquisição daquela como segunda. $\mathrm{O}$ projeto demonstrou a possibilidade de inserção social em atividades do cotidiano, de maneira bastante facilitada, ao utilizar essa abordagem como modelo educacional.

Isso deve ser abarcado por todos os engajados na educação de surdos, os quais, conhecendo as problemáticas envolvidas, possam buscar recursos para implementação de ações inovadoras.

Em relação aos acadêmicos participantes dessa experiência, evidenciou-se a capacidade de criação de novas metodologias, bem como a ressignificação de outras já existentes, respeitando as particularidades dos surdos. Cabe ressaltar o desenvolvimento da reflexão crítica em relação à educação dos surdos sob a perspectiva da abordagem bilíngue. Conscientes dessa realidade, os graduandos se predispuseram a discutir constantemente o ensino, segundo essa abordagem, buscando alternativas que permitissem aos alunos surdos usufruírem do direito de aprender com igualdade.

Embora o relato não aborde aspectos referentes à formação de professores, entende-se a necessidade de esse assunto ser contemplado, de forma densa, em discussões futuras, uma vez que contribuições referentes a programas e técnicas de formação de professores estão intimamente relacionadas à transformação do ensino em questão.

Além disso, cabe dar destaque ao envolvimento das instituições de ensino superior, que são singulares para incentivar reflexões que proporcionem práticas de ensino aos acadêmicos das diferentes áreas, desde a formação inicial, até a continuada. Sabe-se que várias ações realizadas em prol dos surdos são desenvolvidas nessas instâncias educacionais e o projeto EAMES, ainda funcionando na UFV, é uma delas. 
Simultaneamente, os alunos surdos foram contemplados de modo significativo, pois foram observadas grandes mudanças no comportamento linguístico, social, identitário e cultural deles. É inegável, porém, que a aprendizagem da Língua Portuguesa, por esses alunos, encontra-se em processo inicial, devendo ser continuada no decorrer das futuras oficinas desenvolvidas pelo EAMES.

Desse modo, por meio de iniciativas traçadas sob as perspectivas das potencialidades, o frágil processo de escolarização, a que muitos jovens e adultos surdos foram submetidos, pode ser resgatado. Os alunos surdos, depois de finalizarem o ensino médio, precisam ter adquirido conhecimentos semelhantes àqueles referentes à etapa da sua escolaridade, principalmente no que se refere às habilidades de leitura e escrita em Língua Portuguesa. Só assim eles terão possibilidades de ingressar no mercado de trabalho, dar continuidade aos seus estudos por meio do ingresso no ensino superior e de cumprir com seu papel de cidadãos, usufruindo de todas as oportunidades que esse mundo pode lhes oferecer.

Assim, este artigo evidenciou que o ensino e a aprendizagem da Língua Portuguesa como segunda língua para surdos, devem ser essencialmente pautados na LIBRAS e devem considerar as especificidades desses sujeitos. Por fim, este estudo indica a possibilidade de reflexões acerca de recursos didáticos facilitadores que promovam a aprendizagem de jovens e adultos surdos. A adoção de imagens visuais, o uso de recursos concretos e atividades práticas devem ser explorados com o objetivo de possibilitarem uma metodologia adequada às potencialidades dos alunos surdos, possibilitando a real aprendizagem da segunda língua.

\section{Referências Bibliográficas}

BRASIL. Lei $\mathbf{n}^{\mathbf{0}}$. 10.436, de Lei $\mathbf{N}^{\mathbf{0}}$ 10.436, de 24 de abril de 2002, Brasília: MEC, 2002.

CAPOVILA, Fernando Cesar; RAPHAEL, Walkiria Duarte; LUZ, Renato D. "Capítulos introdutórios". In: CAPOVILA, Fernando Cesar; RAPHAEL, Walkiria Duarte. Dicionário enciclopédico ilustrado trilíngue da língua de sinais brasileira. volume II: Sinais de M a Z. 2. ed. São Paulo: Editora da Universidade de São Paulo; Imprensa Oficial do Estado, 2001.

CELANI, Maria Antonieta Alba. "Relevância da Linguística aplicada na formação de uma política educacional brasileira". In: FORTKAMP, M. B. Aspectos da linguística aplicada: estudos em homenagem ao professor Hilário Inácio Bhon. Florianópolis: Insular, 2000, p. 19-20.

CORREIA, Claudio Manoel de Carvalho; FERNANDES, Eulália. "Bilinguismo e Surdez: a evolução dos conceitos no domínio da linguagem". In: FERNANDES, Eulália. (Org.). Surdez e bilinguismo. Porto Alegre: Mediação, 2005, p. 7-25. 
CRUZ, José ldon Gonçalves; DIAS, Tárcia Regina da Silveira. "Trajetória escolar do surdo no ensino superior: condições e possibilidades". Revista Brasileira de Educação Especial, v.5, n.1, p. 65-80, 2009.

DIZEU, Liliane Correia Toscano de Brito; CAPORALI, Sueli Aparecida. "A língua de sinais constituindo o surdo como sujeito". Revista Educação e Sociedade, Campinas, v. 26, n. 91 , p. 583-597, 2005.

FERNANDES, Eulália; RIOS, Kátia Regina. "Educação com bilinguismo para crianças Surdas". Intercâmbio, São Paulo: PUCSP, v. 2, p. 13-21, 1998. Disponível em: <www2. lael.pucsp.br/intercambio/07fernandes-rios.ps.pdf>. Acesso em: 05 maio 2012.

FERNANDES, Eulália. Linguagem e surdez. Porto Alegre: Artmed, 2003.

FERREIRA BRITO, L. Integração social \& educação de surdos. Rio de Janeiro: Babel Editora, 1993.

FREIRE, Paulo. Pedagogia do oprimido. 7. ed. Rio de Janeiro: Paz e Terra, 1979.

Pedagogia da esperança: um reencontro com a pedagogia do oprimido. Rio de Janeiro: Paz e Terra, 1992.

GESSER, Audrei. LIBRAS? Que língua é essa? Crenças e preconceitos em torno da língua de sinais e da realidade surda. São Paulo: Parábola, 2009.

GESUELI, Zilda Maria; MOURA, Lia. "Letramento e Surdez: A Visualização das Palavras”. ETD - Educação Temática Digital, Campinas, v. 7, n. 2, p. 110-122, jun. 2006.

GIORDANI, Liliane Ferrari. "Língua escrita: letras (im) prováveis na educação de jovens e adultos surdos". ETD - Educação Temática Digital, Campinas, v. 7, n. 2, p. 88-97, jun. 2006.

GOÉS, Maria Cecília Rafael. Linguagem, surdez e educação. Campinas, SP: Autores Associados, 1996.

GOLDFELD, Márcia A. Criança surda: A linguagem numa perspectiva sóciointeracionista. 2. ed. São Paulo: Plexus, 2002.

KEATING, Elizabeth; MIRUS, Gene. "American Sign Language in virtual space: Interactions between deaf users of computer-mediated video communication and the impact of technology on language practices". Journal Language in Society, Cambridge University Press, v. 32, p. 693-714, 2003.

LACERDA, Cristina Broglia Feitosa de. "A inclusão escolar de alunos surdos: o que dizem alunos, professores e intérpretes sobre esta experiência”. Cad. Cedes, Campinas, v. 26, n. 69, p. 163-184, maio/ago. 2006. Disponível em: 
<http://www.cedes.unicamp.br>. Acesso em: 15 jun. 2012.

LODI, Ana Claudia Balieiro; MOURA, Maria Cecilia. "Primeira língua e constituição do sujeito: uma transformação social”. ETD - Educação Temática Digital, Campinas, v. 7, n. 2, p. 1-13, jun. 2006.

LOPES, Luiz Paulo da M. Oficina de Linguística Aplicada: a natureza social e educacional dos processos de ensino/aprendizagem de línguas. São Paulo: Mercado de Letras, 1996.

MENEZES, Roony Diogenes. "Produção de um atlas com os sinais na LIBRAS das principais cidades de Pernambuco". In: III CONGRESSO NACIONAL DE TRADUÇÃO E INTERPRETAÇÃO DE LIBRAS E LÍNGUA PORTUGUESA, 3, 2012, Florianópolis. Anais... Florianópolis: Copyright, 2012. Disponível em: <http://www.congressotils.com.br/anais/tils2012_politicasdetraducao_menezes.pdf >. Acesso em: 03 set. 2012.

NERY, Clarisse Alabarce; BATISTA, Cecília Guarnieri. "Imagens visuais como recursos pedagógicos na educação de uma adolescente surda: um estudo de caso". Paidéia, v. 14, n. 29, p. 287-299, 2004.

QUADROS, Ronice Muller de. Educação de surdos: a aquisição da linguagem. Porto Alegre: Artes Médicas, 1997.

INES, 1998.

"O contexto escolar do aluno surdo e o papel das línguas". Revista Espaço,

Phrase structure of Brazilian Sign Language. 1999. Tese. Pontifícia Universidade Católica do Rio Grande do Sul. Porto Alegre, RS: Pontifícia Universidade Católica do Rio Grande do Sul, 1999.

. "O "Bi” em bilinguismo na educação de surdos". In: FERNANDES, Eulália. (Org.) Surdez e bilinguismo. Porto Alegre: Mediação, 2005, p. 26-36.

ROCHA, Grasielly Rabelo. A alfabetização/letramento de crianças surdas: a importância do professor bilíngue. 2010. Trabalho de conclusão do curso de Pedagogia. Faculdade Alfredo Nasser. Goiânia: ISE, 2010.

RODRIGUES, Cristiane Alves Silva et al. Fundação Catarinense de Educação Especial. Política para educação de Surdos no Estado de Santa Catarina. São José - SC: FCEE, 2004.

SALLES, Heloisa Maria Moreira Lima; FAULSTICH, Enilde; CARVALHO, Orlene Lúcia et al. Ensino de Língua Portuguesa para surdos. Caminhos para a prática pedagógica. Brasília: MEC/SEESP, 2004. 
SOFIATO, Cássia Geciauskas. O desafio da representação pictórica da Língua de Sinais Brasileira. 2005. Dissertação. Instituto de Artes da Universidade Estadual de Campinas, Campinas, 2005.

STOKOE, William. Sign language structure: an outline of the visual communication systems of the American deaf. $2^{\text {nd }}$ ed. Maryland: Linstok Press, 1960.

STROBEL, Karin L. Uma menina chamada Kauana. Adaptação para o SignWriting por M. R. Stumpf e A. C. Rocha. Belo Horizonte, MG: Federação Nacional de Educação e Integração dos surdos, 1995. Disponível em: <http://SignWriting.org>. Acesso em: 10 ago. 2012.

STUMPF, Mariane. "SignWriting e a Computação no currículo da escola especial concórdia da Ulbra". Anais do seminário surdez, cidadania e educação. Rio de Janeiro, RJ: Instituto Nacional de Educação de surdos, 1998, p. 71-80.

VELOSO, Ana Carolina Siqueira. A alfabetização do indivíduo surdo: Primeiro em LIBRAS ou em Português? Universidade do Estado do Rio de Janeiro, 2006.

VITAL, Lidiane Aparecida. A contribuição da Língua Brasileira de Sinais (LIBRAS) à aprendizagem significativa da Língua Portuguesa: relato de uma experiência. 2011. Monografia. Centro de Ciências Humanas Letras e Artes. Viçosa MG, Universidade Federal de Viçosa, 2011. 